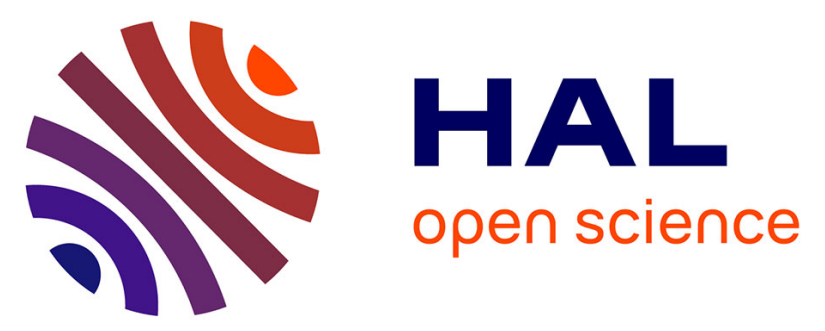

\title{
Thermal aging kinetic and effects on mechanical behavior of fully recycled composite based on polypropylene/polyethylene blend
}

S. Tamboura, A. Tcharkhtchi, H Bendaly, J Fitoussi, Hassen Meftah

\section{- To cite this version:}

S. Tamboura, A. Tcharkhtchi, H Bendaly, J Fitoussi, Hassen Meftah. Thermal aging kinetic and effects on mechanical behavior of fully recycled composite based on polypropylene/polyethylene blend. Journal of Applied Polymer Science, 2018, 135, pp.Article number 46640. 10.1002/app.46640 . hal01900799

\section{HAL Id: hal-01900799 \\ https://hal.science/hal-01900799}

Submitted on 22 Oct 2018

HAL is a multi-disciplinary open access archive for the deposit and dissemination of scientific research documents, whether they are published or not. The documents may come from teaching and research institutions in France or abroad, or from public or private research centers.
L'archive ouverte pluridisciplinaire HAL, est destinée au dépôt et à la diffusion de documents scientifiques de niveau recherche, publiés ou non, émanant des établissements d'enseignement et de recherche français ou étrangers, des laboratoires publics ou privés. 


\title{
Thermal aging kinetic and effects on mechanical behavior of fully recycled composite based on polypropylene/polyethylene blend
}

\author{
S. Tamboura, ${ }^{1}$ H. Meftah $\mathbb{D}^{1},{ }^{1,2}$ J. Fitoussi, ${ }^{2}$ H. BenDaly, ${ }^{1}$ A. Tcharkhtchi ${ }^{2}$ \\ ${ }^{1}$ LMS, ENISo, Université de Sousse, BP 264 Cité Erriadh, Sousse 4023, Tunisie \\ Laboratoire PIMM, UMR 8006 CNRS, Arts et Métiers Paris-Tech, Paris 75013, France \\ Correspondence to: H. Meftah (E-mail: mefteh.hassen988@gmail.com)
}

\begin{abstract}
The effect of thermal oxidation of a fully recycled carbon fibers reinforced stabilized polypropylene/polyethylene blend on the mechanical properties has been studied at 120,130 and $140^{\circ} \mathrm{C}$. In a first step, several analyses by FTIR and UV spectrometry and differential scanning calorimetry were performed in order to detect and monitor the evolution of the antioxidants and oxidation products in the materials. This approach aims to well understand and identify the aging mechanisms that will be modeled in a second step in a kinetic model capable of predicting the evolution of carbonyl build-up while taking into account the presence of the different antioxidants. Modeling results showed a good correlation between the kinetic behavior and the obtained experimental data. Furthermore, the effect of thermal aging on the mechanical behaviors of the composite and the matrix were studied at the macroscopic scale at different strain rates. It has been shown that the thermal oxidation affects only the elongation at break. The numerical values of the oxidation products generated by the kinetic model allowed linking the evolution of the mechanical behavior under aging with the physicochemical state of the material.
\end{abstract}

\section{INTRODUCTION}

The worldwide use of composite materials in several applications has shown an exponential increase during the past decades thanks to their lightness and mechanical performance. ${ }^{1}$ In consequence, wastes from manufacturing and end-of-life products increased as well. Therefore, environmental awareness has increased and led to new global agreements to use more and more recyclable material. ${ }^{2}$

Because of their complex compositions (fibers, matrix, and fillers), it is difficult to completely recycle the composites. For this reason, in the majority of the cases only fibers can be reclaimed using several techniques. Among them is the pyrolysis which is the most widespread used technic to recover fibers. ${ }^{2,3}$ In fact, after pyrolysis, the recycled carbon fibers keep more than $90 \%$ of their mechanical properties. ${ }^{4,5}$ Furthermore, the recycling of polymers has developed during the last two decades. New chemical techniques allow to recycle polymers and reused them as raw materials for new polymer using suitable chemical solvents. ${ }^{6}$

The current study focus on a recycled stabilized blend (polypropylene/polyethylene) reinforced up to $20 \%$ wt with recycled short carbon fibers obtained by pyrolysis and milled in order to get an average length of $180 \mu \mathrm{m}$. The proposed polymer contains two kinds of stabilizers: one is a phenolic and the second is an organic phosphites. The elaborated composite is intended for automotive applications to absorb higher crashworthiness in a harsh environment (near to the engine where the temperature is relatively high). Thus the composite is subjected to physical and chemical aging condition which may degrade the material during its life time and alter the mechanical performance of the part. Therefore, automakers must take into account the parallel effect of chemical ageing (e.g., oxidation) and mechanical ageing (for example fatigue) on applied performance (e.g., crashworthiness application). In fact, the mechanical behavior of an aged bumper for example during an accident is different from the virgin one. So, in order to increase time to embrittlement and so improve the mechanical properties, agents and stabilizer are added to polymers during extrusion or injection molding.

To characterize the phenomena involved in stabilizer disappearance, a good understanding of its physico-chemistry is required. In fact, this latter can be consumed not only by chemical reactions but also lost by extraction or evaporation and many researches have been realized studying its effect on polymers ageing in terms of its induction period and its consumption rate. $^{7-9}$ In order to be able to detect antioxidants, follow their 
disappearance and carbonyls build up, many analytical methods are proposed in literature such as IR and UV spectrophotometry and differential scanning calorimetry (DSC) under oxygen (OIT) ${ }^{10-14}$ Coupling the chemical consumption and physical loss of stabilizers and proposing valid kinetic models is a complex and interesting field that's why in recent years many researchers have been attracted to study it. ${ }^{15,16}$

This work aims to study in one hand, the thermal aging of the two materials mentioned above, characterize the stabilizer influence on the induction period and propose a kinetic model capable of predicting the consumption of the antioxidants, the induction time and the carbonyl build-up evolution. The mechanistic scheme involving stabilizer used in the current work was used in previous work and some assumptions have been made to simplify the mechanism and the modeling. ${ }^{17-19}$ In the other hand, the effect of oxidation on the mechanical behavior is studied in order to link the thermal aging influence on the embrittlement of the composite and the matrix in the quasistatic and dynamic loading.

\section{EXPERIMENTAL}

\section{Materials}

In this work, two materials are proposed. The first is a $100 \%$ recycled polypropylene/polyethylene blend matrix (RPP) designed for crashworthiness in automotive applications. A phenolic antioxidant and an organic phosphites, more precisely the tri (alkylaryl) phosphites, have been added to the matrix during elaboration process in order to better withstand environmental temperatures and delay oxidation. For confidential reasons, the exact structure and formula of the stabilizers will not be communicated. The second material used in this work is a composite made of the RPP matrix and a $20 \%$ of short recycled carbon fibers obtained by pyrolysis and then milled. The recycled fibers have a density of $1.8 \mathrm{~g} / \mathrm{cm}^{-3}$, a diameter of $7 \mu \mathrm{m}$ and a nominal length of $180 \mu \mathrm{m}$. The composite plates were first elaborated by extrusion in order to obtain a homogeneous matrix-fibers compound and then by injection molding. As for the matrix plates, they were obtained only by injection molding. The elaboration process configurations are more detailed in Ref. 20.

\section{Characterization}

Film Purification. In the literature, some authors were able to identify IR peaks related to the phosphites that others could not. $^{22-25}$ So to better identify the peaks corresponding to the two antioxidants and to monitor their consumption during aging using FTIR and UV spectrophotometry, the phenol and phosphites were extracted for analyzing. The purification was performed on RPP and RPP-CF180 films having an average thickness of $25 \mu \mathrm{m}$ and obtained by microtoming. The extraction procedure was carried out using a chloroform-ethanolhexane (1:1:4) mixture under reflux for $48 \mathrm{~h}$ and then dried under vacuum at $40{ }^{\circ} \mathrm{C} .{ }^{21}$ After extraction operation, the residual sample was dried to obtain the pure stabilizer.

Infra-Red Spectrophotometry. FTIR spectrophotometry was performed in transmission mode on free standing films using a Frontier spectrophotometer (PerkinElmer). For each test, 32 scans were averaged in the 400 to $4000 \mathrm{~cm}^{-1}$ wavenumber range to be able to obtain a $4 \mathrm{~cm}^{-1}$ resolution. The obtained spectra were analyzed using Spectrum software (PerkinElmer) in order to determine the absorbance value and therefor the concentrations of oxidant and antioxidant products by using Beer Lambert law:

$$
A=\varepsilon_{\lambda} \cdot 1 \cdot C_{\lambda}
$$

where $A$ is the absorbance value, $\varepsilon_{\lambda}\left(\mathrm{L} \mathrm{mol}^{-1} \mathrm{~cm}^{-1}\right)$ the molar absorptivity taken equal to $\varepsilon_{3646}=117 \mathrm{~L} \mathrm{~mol}^{-1} \mathrm{~cm}^{-1}$, $\varepsilon_{1743}=590 \mathrm{~L} \mathrm{~mol}^{-1} \mathrm{~cm}^{-1}, \varepsilon_{1718}=350 \mathrm{~L} \mathrm{~mol}^{-1} \mathrm{~cm}^{-1}, \varepsilon_{768}=$ $440 \mathrm{~L} \mathrm{~mol} \mathrm{~cm}^{-1}, \varepsilon_{887}=318 \mathrm{~L} \mathrm{~mol}^{-1} \mathrm{~cm}^{-1}, \varepsilon_{1195}=350$ $\mathrm{L} \mathrm{mol}{ }^{-1} \mathrm{~cm}^{-1}, \varepsilon_{1234}=250 \mathrm{~L} \mathrm{~mol}^{-1} \mathrm{~cm}^{-1}{ }^{22-26}$ (Typical Infrared Absorption Frequencies) $\mathrm{L}(\mathrm{cm})$ is the film thickness and $C_{\lambda}\left(\mathrm{mol} \mathrm{L}^{-1}\right)$ is he concentration of the considered species.

UV Spectrophotometry. Beside the IR spectrophotometry, UV analyzes were performed to follow the concentration evolution of the phenolic function. Since the concentration of phenolic stabilizer is very low $(<1 \%)$, its value obtained by FTIR spectroscopy is not accurate. To do so, tests have been realized using a UV Perkin Elmer Lamba 35 Spectrophotometer.

Oxidation Induction Time Measurements. To characterize the presence of antioxidant in the matrix and composite, DSC tests under oxygen were performed in the aim of measuring the oxidation induction time (OIT). The experiments were realized on 4-7 mg mass samples heated from 50 to $200^{\circ} \mathrm{C}$ at a heat rate of $10^{\circ} \mathrm{C} \min ^{-1}$ under 1 bar of pure oxygen with a gas flow maintained at $50 \mathrm{~mL} / \mathrm{min}$.

Mechanical Characterization. Mechanical behavior of RPP and RPP-CF180 throw thermal aging was characterized under dynamic (high speed strain rate) and quasi-static loading. Dynamic tests were realized at $10 \mathrm{~s}^{-1}$ strain rate using a servohydraulic test machine (Schenck) equipped with a high speed camera (FASTCAM-APX RS) with the capacity of 250,000 frames per second to be able to record the pictures during high speed tensile test. The geometry of the specimen was optimized using ABAQUS finite element code in order to obtain a homogeneous strain distribution and a continued strain rate in the specimen's effective zone. ${ }^{20}$ The quasi-static tests were performed at $10^{-2} \mathrm{~s}^{-1}$, using INSTRON tensile-compression electromechanical device on specimen respecting ISO 527-2:1996 type $5 \mathrm{~A}$.

Exposure Conditions. Thermal aging under atmospheric air was carried out in ventilated oven at 120,130 , and $140{ }^{\circ} \mathrm{C}$ on matrix and composites films and specimens.

\section{RESULTS AND DISCUSSION}

\section{FTIR Analysis}

Figure 1 shows the infra-red spectrum of RPP matrix before and after purification. One can notice the presence of two peaks at 1743 and $3646 \mathrm{~cm}^{-1}$ related to the ester group and phenol function of the first antioxidant, respectively. Furthermore, four peaks related to the phosphites stabilizer are present: two medium at $768,876 \mathrm{~cm}^{-1}$, a weak one at $1195 \mathrm{~cm}^{-125}$ and a strong peak at $1234 \mathrm{~cm}^{-1}$ corresponding to the phosphonate (Typical Infrared Absorption Frequencies). The Ester absorption has a higher molar absorptivity than the phenol and does not 

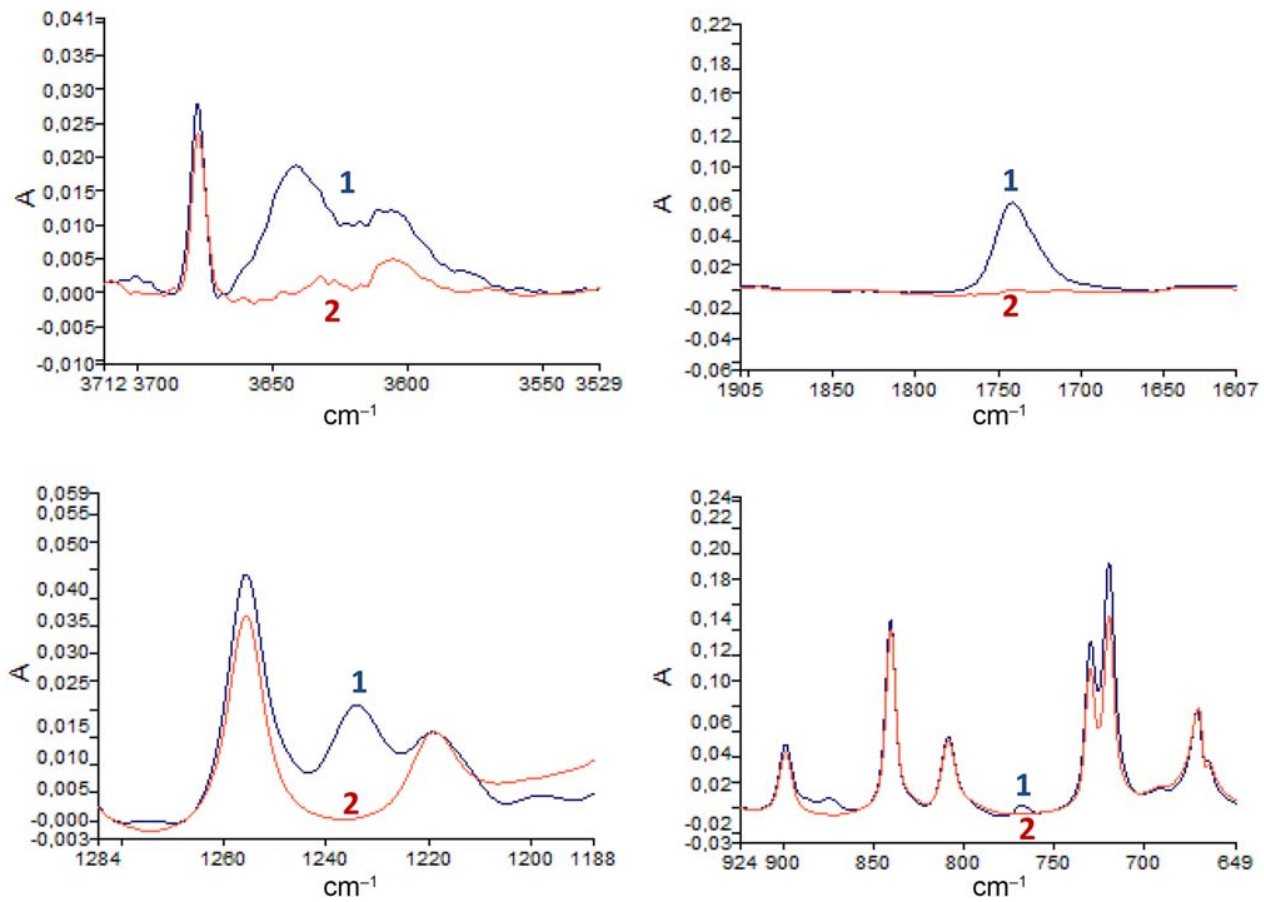

Figure 1. IR specter of RPP before (1) and after (2) stabilizer extraction. [Color figure can be viewed at wileyonlinelibrary.com]

interfere with the matrix absorption meantime $\mathrm{OH}$ signal does. ${ }^{26}$ The same results were validated in the case of the composite.

\section{OIT Measurements}

Figure 2 shows measurement result of the OIT at $200{ }^{\circ} \mathrm{C}$ of the RPP matrix. It shows two endothermic peaks at 127 and $163^{\circ} \mathrm{C}$ corresponding to the melting temperature of the polyethylene and polypropylene present in the blend respectively followed by a constant plateau due to the anti-oxidizing effect. After 343 min, an exothermic peak appears due to the oxidization of the material. It should be noted that a non-stabilized polypropylene that shows an average of OIT of 5 min. ${ }^{27} \mathrm{~A}$ comparison between the OIT of the two materials is illustrated in Figure 3. This figure shows a lower OIT, about $331 \mathrm{~min}$, for the composite compared to the pure matrix. This difference can be explained by a consumption of a part of the antioxidants during the extra extrusion process that the composite has undergone. This decrease of the antioxidant quantity will have a direct impact on the induction time.

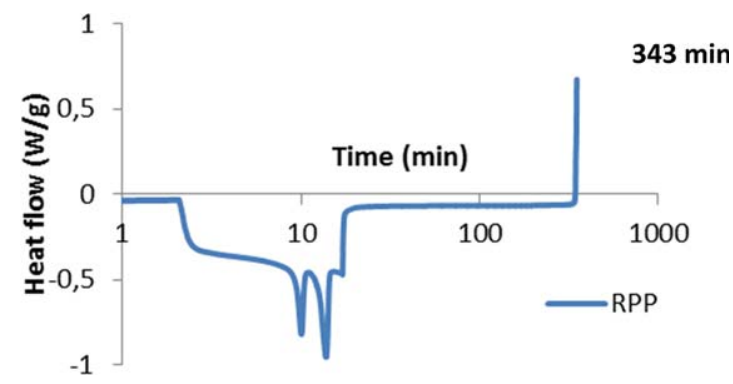

Figure 2. Oxidation induction time (OIT) measurement for the RPP matrix. [Color figure can be viewed at wileyonlinelibrary.com]

\section{Carbonyl Build-Up and Stabilizers Disappearance}

FTIR spectra evolution of the RPP matrix during exposure at $140^{\circ} \mathrm{C}$ is shown in Figure 4. During exposure, the absorbance of ester peak (at $1742 \mathrm{~cm}^{-1}$ ) decreases as another start to appear and increases at $1718 \mathrm{~cm}^{-1}$ which corresponds to the carbonyl build-up. The distinction between these different groups is not easy from a theoretical and experimental point of view. In fact, carbonyl and ester group are superposed in the same absorption peak. So, to be able to measure the real contribution of each group, a Gaussian deconvolution, using Origin Lab software was necessary. Once the spectrum deconvoluted, and by applying Beer Lambert law, mentioned above, the evolutions of ester and carbonyl groups are determined. Figure 5(a) compares the evolution of carbonyl group in the matrix and in the composite at $140^{\circ} \mathrm{C}$. One can note that the oxidation products appear and stabilize in the form of a plateau faster in the case of the composite. Thermal aging follow-up was stopped after 175 and $359 \mathrm{~h}$ for the composite and the matrix respectively. Since the ester group is not involved in the stabilization reactions, it is considered chemically stable. Thus, the evolution

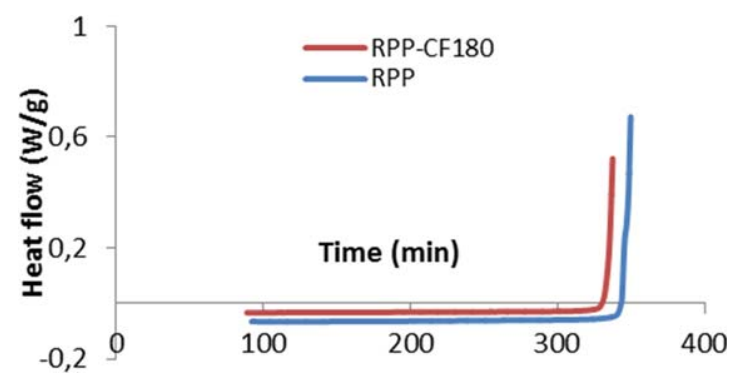

Figure 3. Comparison between OIT measurement for the matrix and the composite. [Color figure can be viewed at wileyonlinelibrary.com] 


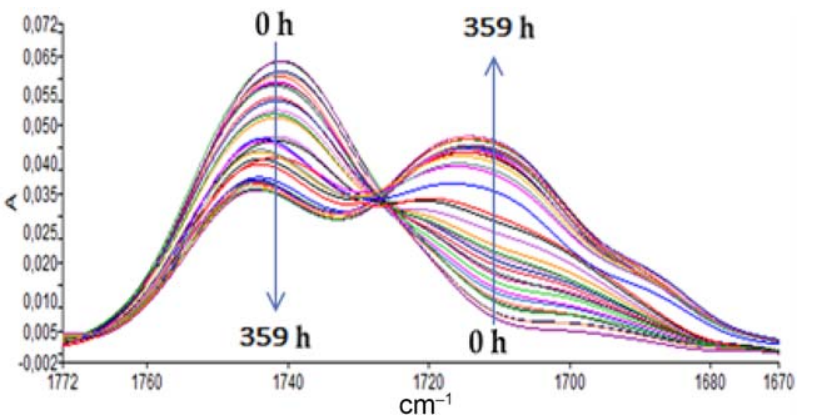

Figure 4. FTIR spectra of RPP matrix at $140^{\circ} \mathrm{C}$. [Color figure can be viewed at wileyonlinelibrary.com]

of its optical density will directly inform us about its physical loss, because of the evaporation. ${ }^{24}$ Ester band starts to disappear from the very first moments of exposure and decays almost linearly as shown in Figure 5(b). It is obvious that the ester group in the composite decreases faster than RPP which affects the induction time and consequently the carbonyl build up rate. The maximum rate of the ester group loss (initial slope of the curves) is an increasing function of temperature. This rate are grouped in Table II for each exposure temperatures. As it can be seen, the ester groups disappear rapidly with the increase of exposure temperature. As for the evolution of the phenol concentration [Figure 5(c)], it shows a drop during the induction period followed by a plateau. Its evolution and concentration are different compared to literature. In fact, several works have shown that the phenol group disappears by chemical reaction and physical loss before the induction time is reached and its concentration value is much lower than the one shown in Figure 5(c). ${ }^{15}$ Thus, one can suppose that another additive product is present at the same spectral range as the phenol; and its concentration does not change during the induction period. However, the results of the purification show previously in Figure 1 show that it is not possible to detect the presence of any other

(a)

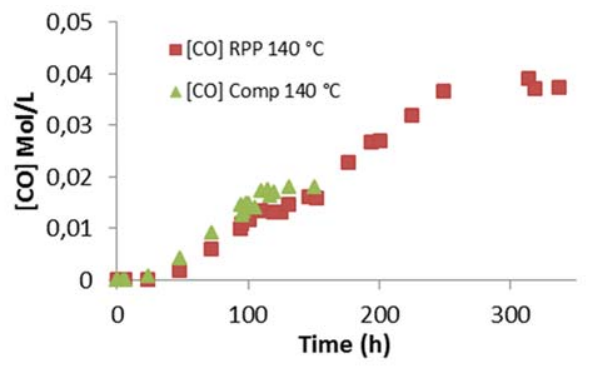

(c)

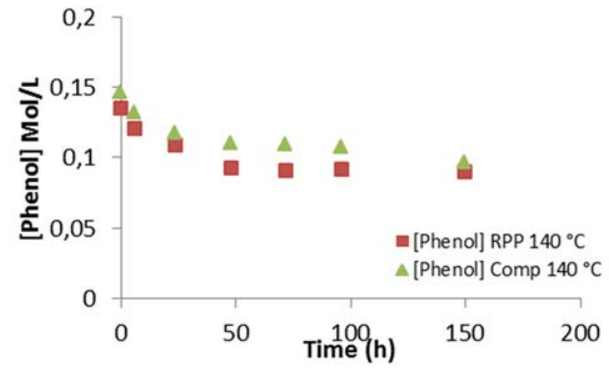

product. Thus, the concentration evolution of this stabilizer will be realized through UV spectrometry and discussed in the following paragraph. Figure 5(d), represents the phosphites concentration decrease for the composite and the matrix. It shows that in one hand the initial concentration of this antioxidant is higher in the matrix than in the composite $(0.0399 \mathrm{~mol} / \mathrm{L} \mathrm{com}-$ pared to $0.0375 \mathrm{~mol} / \mathrm{L}$ ) and in the other hand that this stabilizer is not totally consumed during the induction period but in the contrast, it disappears once the oxidation process stabilizes and it happens first in the case of the composite. It has been verified for each exposition temperature that the oxidation in the composite appears faster than in the matrix. Table I summarizes the induction time $\left(t_{i}\right)$ for the two materials for each exposure temperature.

The UV spectrometry analysis of the two materials though aging at $140{ }^{\circ} \mathrm{C}$ is shown in Figure 6. The results show a wide UV absorption band consisting of two contributions between 250 and $300 \mathrm{~nm}$ related to the phenolic and phosphites antioxidants.

Since phosphites stabilizers have an aromatic group that contributes in the absorbance at $283 \mathrm{~nm}$, it was not possible to determine exactly the contribution of phenol from the UV spectrum. To deal with this problem, the contribution of the phosphites aromatic group in the peak is subtracted. For that, the concentration of the latter is calculated thanks to IR spectrum and the UV contribution of phenol is given by the following equation:

$$
[\mathrm{Phenol}]=\frac{A_{283}-[\mathrm{Phos}] \cdot \varepsilon_{\mathrm{Ar}-\mathrm{O}-\mathrm{P}} \cdot l}{l \cdot \varepsilon_{\mathrm{Ar}-\mathrm{OH}}}
$$

where $A_{283}$ is the absorbance peak at $283 \mathrm{~nm}$, [Phos] is the phosphites concentration measured by FTIR spectrometry, $\varepsilon_{\mathrm{Ar}-\mathrm{O}-\mathrm{P}}$ (731 $\left.\mathrm{L} \mathrm{mol}^{-1} \mathrm{~cm}^{-1}\right)$ and $\varepsilon_{\mathrm{Ar}-\mathrm{OH}}\left(1439 \mathrm{~L} \mathrm{~mol}^{-1} \mathrm{~cm}^{-1}\right)$ are the molar absorptivity of phosphites and phenol at $283 \mathrm{~nm}$, respectively. ${ }^{28}$ By applying the precedent formula the initial concentration of phenol is slightly lower than that obtained by subtracting the plateau from the phenol curve in Figure 5(c). The kinetic curves of

(b)

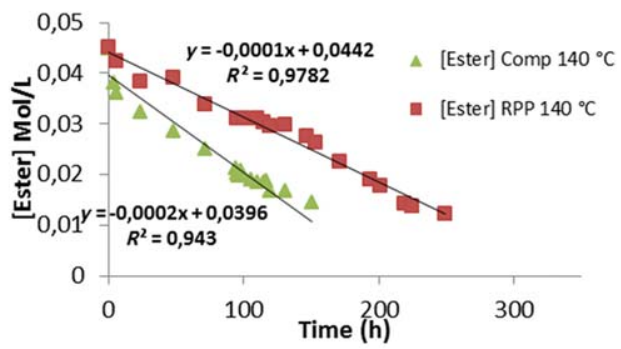

(d)

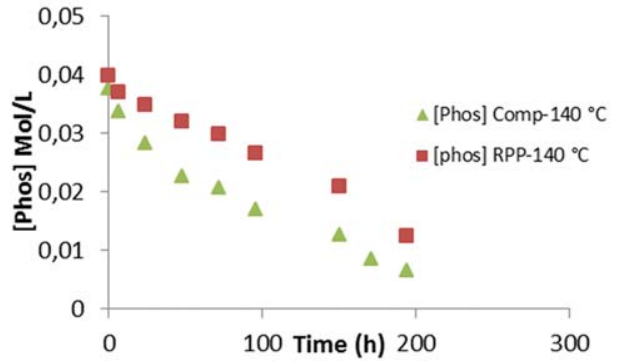

Figure 5. Comparison between kinetic curves for RPP and the composite at $140{ }^{\circ} \mathrm{C}$ : (a) carbonyl build-up, (b) ester group, (c) phenol, and (d) phosphites. [Color figure can be viewed at wileyonlinelibrary.com] 
Table I. Induction Time for the Matrix and the Composite for Each Exposure Temperature

\begin{tabular}{llll}
\hline $\begin{array}{l}\text { Temperature }\left({ }^{\circ} \mathrm{C}\right) \\
\text { Induction time } t_{i}(\mathrm{~h})\end{array}$ & 120 & 130 & 140 \\
\hline RPP & 175 & 60 & 42 \\
RPP-CF180 & 95 & 36 & 24 \\
\hline
\end{tabular}

Phenol concentration consumption of the matrix and composite at $140{ }^{\circ} \mathrm{C}$ are represented in Figure 7. Contrary to the results shown previously in Figure 5(c), these results show that the initial value of the concentration of phenols is in a concentration range similar to that found in the literature. ${ }^{15}$ Moreover, the phenol concentration present in the matrix $\left(0.0375 \mathrm{~mol} \mathrm{~L}^{-1}\right)$ is greater than that of the composite $\left(0.0307 \mathrm{~mol} \mathrm{~L}^{-1}\right)$. In addition, these results show that the phenolic antioxidant is fully consumed before the induction time. Therefore, the shorter induction time in the case of the composite is explained by a lower initial concentration of the phenolic antioxidant.

\section{Kinetic Model}

A standard mechanism has been chosen considering both uniand bimolecular hydroperoxide decomposition ${ }^{29}$ and taking into account the antioxidants effect. ${ }^{30-32}$ This mechanism is given by the following scheme:

$\begin{array}{lll}(\mathrm{Iu}) \mathrm{POOH} & \rightarrow 2 \mathrm{P}^{\circ}+\mathrm{Y}_{\mathrm{CO}} \mathrm{PC}=\mathrm{O} & \mathrm{K}_{1 \mathrm{u}} \\ (\mathrm{Ib}) \mathrm{POOH}+\mathrm{POOH} & \rightarrow \mathrm{P}^{\circ}+\mathrm{POO}^{\circ}+\mathrm{Y}_{\mathrm{CO}} \mathrm{PC}=\mathrm{O} & \mathrm{K}_{1 \mathrm{~b}} \\ (2) \mathrm{P}^{\circ}+\mathrm{O}_{2} & \rightarrow \mathrm{POO}^{\circ} & \mathrm{K}_{2} \\ (3) \quad \mathrm{POO}^{\circ}+\mathrm{PH} & \rightarrow \mathrm{POOH}^{\circ} \mathrm{P}^{\circ} & \mathrm{K}_{3} \\ (4) \mathrm{P}^{\circ}+\mathrm{P}^{\circ} & \rightarrow \text { inactive product } & \mathrm{K}_{4} \\ (5) \mathrm{P}^{\circ}+\mathrm{POO}^{\circ} & \rightarrow \text { inactive products } & \mathrm{K}_{5} \\ (6) \mathrm{POO}^{\circ}+\mathrm{POO}^{\circ} & \rightarrow \text { inactive products }+\mathrm{O}_{2} & \mathrm{~K}_{6} \\ \text { (S1) } \mathrm{AH}+\mathrm{POO}^{\circ} & \rightarrow \mathrm{A}^{\circ}+\mathrm{POOH} & \mathrm{K}_{\mathrm{S} 1} \\ \text { (S2) } \mathrm{A}^{\circ}+\mathrm{POO}^{\circ} & \rightarrow \mathrm{POO}-\mathrm{A} & \mathrm{K}_{\mathrm{S} 2} \\ \text { (Phos) POOH }+\mathrm{PHOS} \rightarrow \text { inactive products } & \mathrm{K}_{\mathrm{Pho}}\end{array}$

Basing on these reactions, the following set of differential equations is derived:

$$
\begin{aligned}
& \frac{d\left[\mathrm{P}^{\circ}\right]}{d t}=2 k_{1 u}[\mathrm{POOH}]+k_{1 b}[\mathrm{POOH}]^{2}-k_{2}\left[\mathrm{P}^{\circ}\right]\left[\mathrm{O}_{2}\right]+k_{3}\left[\mathrm{POO}^{\circ}\right][\mathrm{PH}] \\
& -2 k_{4}\left[\mathrm{P}^{\circ}\right]^{2}-k_{5}\left[\mathrm{P}^{\circ}\right]\left[\mathrm{POO}^{\circ}\right] \\
& \frac{d\left[\mathrm{POO}^{\circ}\right]}{d t}=k_{1 b}[\mathrm{POOH}]^{2}+k_{2}\left[\mathrm{P}^{\circ}\right]\left[\mathrm{O}_{2}\right]-k_{3}\left[\mathrm{POO}^{\circ}\right][\mathrm{PH}] \\
& -k_{5}\left[\mathrm{P}^{\circ}\right]\left[\mathrm{POO}^{\circ}\right]-2 k_{6}\left[\mathrm{POO}^{\circ}\right]^{2}-k_{s 1}\left[\mathrm{POO}^{\circ}\right][\mathrm{AH}]-k_{s 2}\left[\mathrm{POO}^{\circ}\right]\left[A^{\circ}\right]
\end{aligned}
$$

$$
\begin{gathered}
\frac{d[\mathrm{POOH}]}{d t}=-k_{1 u}[\mathrm{POOH}]-k_{1 b}[\mathrm{POOH}]^{2} \\
+k_{3}\left[\mathrm{POO}^{\circ}\right][\mathrm{PH}]+k_{S 1}\left[\mathrm{POO}^{\circ}\right][\mathrm{AH}]-k_{\mathrm{PHOS}}[\mathrm{POOH}][\mathrm{PHOS}] \\
\frac{d[\mathrm{PH}]}{d t}=-k_{1 u}[\mathrm{POOH}]+k_{3}\left[\mathrm{POO}^{\circ}\right][\mathrm{PH}] \\
\frac{\partial[\mathrm{AH}]}{\partial t}=-k_{s 1}\left[\mathrm{POO}^{\circ}\right][\mathrm{AH}]-\delta_{\mathrm{AH}}[\mathrm{AH}] \\
\frac{d\left[\mathrm{~A}^{\circ}\right]}{d t}=-k_{s 1}\left[\mathrm{POO}^{\circ}\right][\mathrm{AH}]-k_{S 2}\left[\mathrm{POO}^{\circ}\right]\left[\mathrm{A}^{\circ}\right]-\delta_{\mathrm{A}^{\circ}}\left[\mathrm{A}^{\circ}\right] \\
\frac{\partial[\mathrm{PHOS}]}{\partial t}=-k_{\mathrm{PHOS}}[\mathrm{POOH}][\mathrm{PHOS}]-\delta_{\mathrm{Phos}}[\mathrm{PHOS}]
\end{gathered}
$$

where $\delta_{\mathrm{AH}}, \delta_{\mathrm{Phosh}}$, and $\delta_{\mathrm{A}^{\circ}}$ are the evaporation coefficients of phenol and phosphites and their radicals, respectively.

The system was solved numerically using Matlab Ode23s solver with the following boundaries conditions:

- At $t=0:\left[\mathrm{P}^{\circ}\right]=\left[\mathrm{POO}^{\circ}\right]=0$

\begin{tabular}{|c|c|c|c|c|c|c|}
\hline$T\left({ }^{\circ} \mathrm{C}\right)$ & \multicolumn{2}{|c|}{120} & \multicolumn{2}{|c|}{130} & \multicolumn{2}{|c|}{140} \\
\hline $\begin{array}{l}\text { Dispersion rate of the ester } \\
\text { groups }\left(\mathrm{mol} \mathrm{L}^{-1} \mathrm{~s}^{-1}\right)\end{array}$ & $\begin{array}{l}\mathrm{RPP} \\
-2 \times 10^{-9}\end{array}$ & $\begin{array}{l}\text { Composite } \\
-8.3 \times 10^{-9}\end{array}$ & $\begin{array}{l}\mathrm{RPP} \\
-2 \times 10^{-8}\end{array}$ & $\begin{array}{l}\text { Composite } \\
-4.7 \times 10^{-8}\end{array}$ & $\begin{array}{l}\text { RPP } \\
-2.7 \times 10^{-8}\end{array}$ & $\begin{array}{l}\text { Composite } \\
-5.5 \times 10^{-8}\end{array}$ \\
\hline
\end{tabular}

- $[\mathrm{POOH}]_{0}=10^{-4} \mathrm{~mol} \mathrm{~L}^{-1}$

- $[\mathrm{PH}]=24 \mathrm{~mol} \mathrm{~L}^{-1}$

- $\left[\mathrm{O}_{2}\right]=S_{\mathrm{O}_{2}} \times P_{\mathrm{O}_{2}}, S_{\mathrm{O}_{2}}$ being the oxygen solubility in the matrix and $P_{\mathrm{O}_{2}}$ the external oxygen pressure of the atmosphere.

- $\left[\mathrm{A}^{\circ}\right]=0$

The kinetic curves for the carbonyl build-up were generated using the following equation:

Table II. Disappearance Rate of the Ester Group at 120,130 , and $140{ }^{\circ} \mathrm{C}$
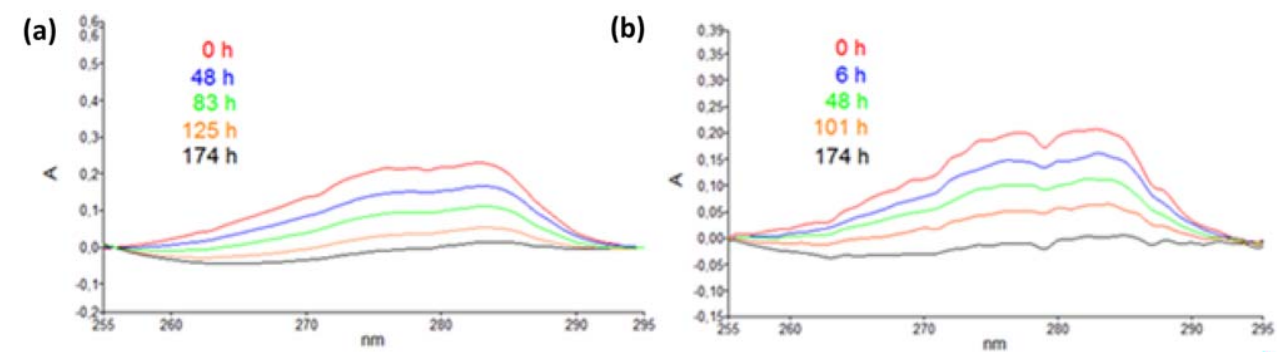

Figure 6. UV spectra evolution of (a) RPP and (b) RPP-CF180. [Color figure can be viewed at wileyonlinelibrary.com] 


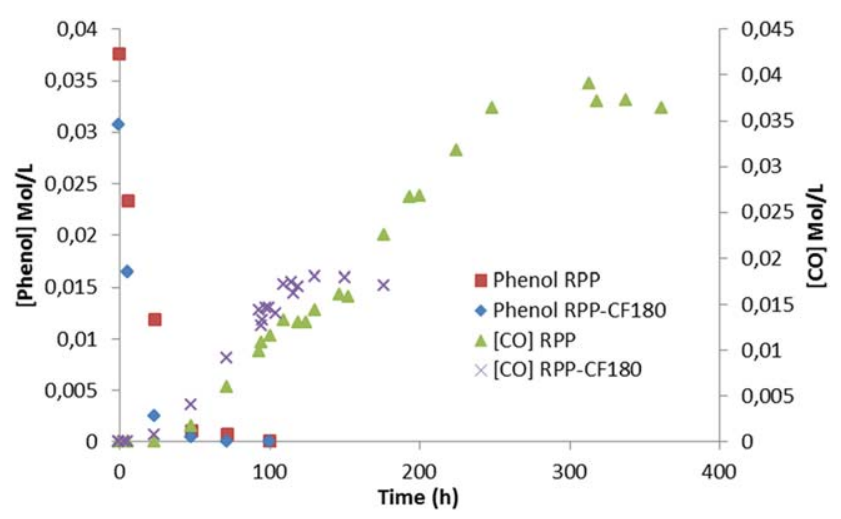

Figure 7. Phenol disappearance through oxidation of RPP and RPPCF180. [Color figure can be viewed at wileyonlinelibrary.com]

$$
\frac{d[P C=0]}{d t}=Y_{\mathrm{CO}_{u}} k_{1 u}[\mathrm{POOH}]+Y_{\mathrm{CO}_{b}} k_{1 b}[\mathrm{POOH}]^{2}
$$

$Y_{\mathrm{CO}_{u}}$ and $Y_{\mathrm{CO}_{b}}$ are the carbonyl yields of the uni- and bimolecular $\mathrm{POOH}$ decomposition, respectively. ${ }^{33}$

Figure $8(\mathrm{a}, \mathrm{b})$ show the different simulations of the carbonyl build-up and phenol extinction for the matrix and the composite at $140^{\circ} \mathrm{C}$. A good correlation between numerical kinetic curves and those obtained experimentally is clearly noticed. Figure 8 (c) represents the numerical and experimental curves of phosphites concentration evolution for the two materials. The rate constants values that provided the best simulations of the experimental results corresponding to the different exposure temperatures are summarized in Table III. The orders of magnitude of the termination rate constants verify the relationship $K_{4} \geq K_{5} \gg K_{6}$ found in the literature. ${ }^{34}$ The rate constants $K_{2}$, $K_{4}$, and $K_{5}$ involving a primary radical $P^{\circ}$ which is very reactive, are independent of the temperature. This indicates that their activation energy is relatively zero. The value of $k_{3}$, responsible for the carbonyl build-up rate, remains approximately the same for the matrix and the composite and increases with the increase of the temperature. The parameters $k_{S 1}, K_{S 2}$, and $k_{\text {Phos }}$ responsible for the disappearance of the different antioxidants are changed. In fact, they increase as well with the increase of the temperature and are lower in the case of the composite since the oxidation occurs faster.

The determination of the model parameters for the tree exposure temperatures (Table III) allowed the calculation of the activation energy corresponding to each parameter. The different values of the activation energies are shown in Table IV. The activation energies values of the initiation and propagation steps calculated are realistic and similar to those found by Richaud et al. ${ }^{19}$

\section{Influence of Thermal Oxidation on the Mechanical Behavior}

The mechanical behavior of the matrix and composite was characterized through tensile tests at quasi-static $\left(10^{-2} \mathrm{~s}^{-1}\right)$ and high strain rate loading $\left(10 \mathrm{~s}^{-1}\right)$. The obtained stress/strain curves of the composite and the matrix specimens, taken at different times of aging at $140^{\circ} \mathrm{C}$, are represented in Figure 9. It is clear that the Young's modulus and the ultimate stress remain the same and are not affected by thermal aging but the elongation at break $\left(E_{r}\right)$ is. Indeed, the elongation at break evolution at the quasi-static rate, illustrated in Figure 10, shows a dramatic drop by $40 \%$ and $45 \%$ for the RPP and RPP-CF180, respectively, from the very first moments of exposure to the induction time followed by a slow decrease until the end of the oxidation which is different from the results found in the literature. In fact Fayolle et al. ${ }^{35,36}$ showed in their work on polypropylene, that the elongation at break is the most affected mechanical parameter by thermal aging. However, its evolution is characterized by a very small decrease during the induction period followed by a dramatic drop once the induction time is
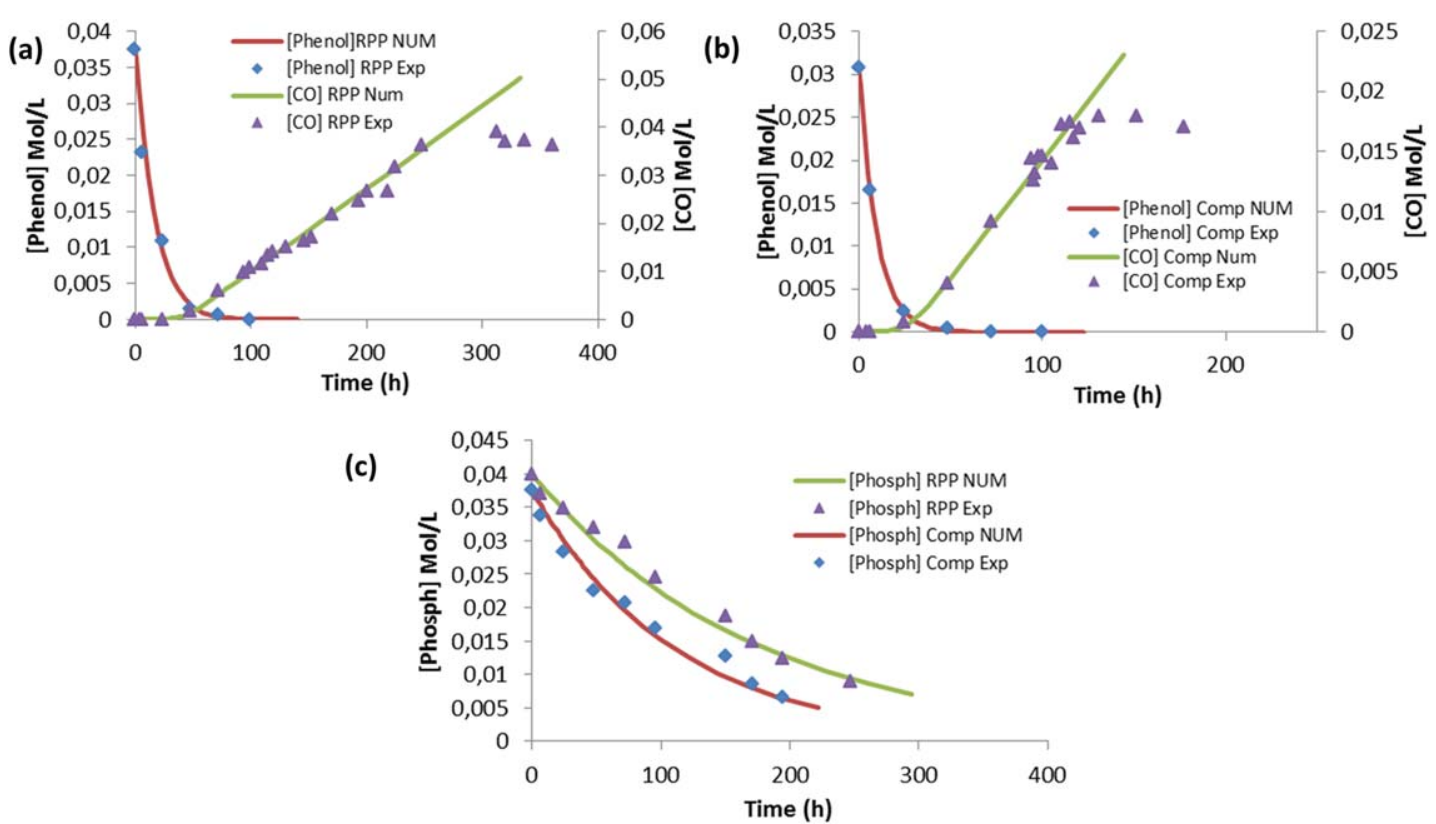

Figure 8. Numerical and experimental kinetic curves at $140{ }^{\circ} \mathrm{C}$ : carbonyl build-up and phenol consumption: (a) composite, (b) matrix (b) and (c) phosphites disappearance. [Color figure can be viewed at wileyonlinelibrary.com] 
Table III. Kinetic Parameters of the RPP and RPP-CF180

\begin{tabular}{|c|c|c|c|c|c|c|}
\hline \multirow{2}{*}{$\frac{\text { Temperature }\left({ }^{\circ} \mathrm{C}\right)}{\text { Parameters }}$} & \multicolumn{2}{|c|}{120} & \multicolumn{2}{|c|}{130} & \multicolumn{2}{|c|}{140} \\
\hline & Matrix & Composite & Matrix & Composite & Matrix & Composite \\
\hline$K_{1 u}\left(s^{-1}\right)$ & $2 \times 10^{-6}$ & $2.5 \times 10^{-6}$ & $7 \times 10^{-6}$ & $9 \times 10^{-6}$ & $10^{-5}$ & $1.6 \times 10^{-5}$ \\
\hline $\mathrm{K}_{1 \mathrm{~b}}\left(\mathrm{~L} \mathrm{~mol}^{-1} \mathrm{~s}^{-1}\right)$ & $2 \times 10^{-3}$ & $2 \times 10^{-3}$ & $8 \times 10^{-3}$ & $7 \times 10^{-3}$ & $10^{-2}$ & $10^{-2}$ \\
\hline $\mathrm{K}_{2}\left(\mathrm{~L} \mathrm{~mol}^{-1} \mathrm{~s}^{-1}\right)$ & $10^{7}$ & $10^{7}$ & $10^{7}$ & $10^{7}$ & $10^{7}$ & $10^{7}$ \\
\hline $\mathrm{K}_{3}\left(\mathrm{~L} \mathrm{~mol}^{-1} \mathrm{~s}^{-1}\right)$ & 0.011 & 0.012 & 0.019 & 0.02 & 0.026 & 0.027 \\
\hline $\mathrm{K}_{4}\left(\mathrm{~L} \mathrm{~mol}^{-1} \mathrm{~s}^{-1}\right)$ & $2 \times 10^{9}$ & $2 \times 10^{9}$ & $2 \times 10^{9}$ & $2 \times 10^{9}$ & $2 \times 10^{9}$ & $2 \times 10^{9}$ \\
\hline$K_{5}\left(L_{\mathrm{mol}^{-1}} \mathrm{~s}^{-1}\right)$ & $10^{8}$ & $10^{8}$ & $10^{8}$ & $10^{8}$ & $10^{8}$ & $10^{8}$ \\
\hline $\mathrm{K}_{6}\left(\mathrm{~L} \mathrm{~mol}^{-1} \mathrm{~s}^{-1}\right)$ & $1.4 \times 10^{6}$ & $2 \times 10^{6}$ & $2.1 \times 10^{6}$ & $2.5 \times 10^{6}$ & $2.9 \times 10^{6}$ & $3.1 \times 10^{6}$ \\
\hline$K_{\mathrm{S} 1}\left(\mathrm{~L} \mathrm{~mol}^{-1} \mathrm{~s}^{-1}\right)$ & $0.12 \times 10^{2}$ & $0.1 \times 10^{2}$ & $0.22 \times 10^{2}$ & $0.14 \times 10^{2}$ & $0.3 \times 10^{2}$ & $0.2 \times 10^{2}$ \\
\hline$K_{\mathrm{S} 2}\left(\mathrm{~L} \mathrm{~mol}^{-1} \mathrm{~s}^{-1}\right)$ & $1.25 \times 10^{10}$ & $1.2 \times 10^{10}$ & $1.35 \times 10^{10}$ & $1.3 \times 10^{10}$ & $1.5 \times 10^{10}$ & $1.4 \times 10^{10}$ \\
\hline$K_{\text {Phos }}\left(L_{\left.\mathrm{mol}^{-1} \mathrm{~s}^{-1}\right)}\right.$ & $6 \times 10^{-6}$ & $5 \times 10^{-6}$ & $1.5 \times 10^{-5}$ & $1 \times 10^{-5}$ & $2.5 \times 10^{-5}$ & $2 \times 10^{-5}$ \\
\hline$\delta_{A H}$ & $0.45 \times 10^{-5}$ & $0.7 \times 10^{-5}$ & $0.82 \times 10^{-5}$ & $1 \times 10^{-5}$ & $0.16 \times 10^{-4}$ & $0.28 \times 10^{-4}$ \\
\hline$\delta_{A^{\circ}}$ & $10^{-3}$ & $10^{-3}$ & $10^{-3}$ & $10^{-3}$ & $10^{-3}$ & $10^{-3}$ \\
\hline B Phos & $0.4 \times 10^{-6}$ & $0.45 \times 10^{-6}$ & $0.8 \times 10^{-6}$ & $1.8 \times 10^{-6}$ & $1.6 \times 10^{-6}$ & $2.5 \times 10^{-6}$ \\
\hline$Y_{\mathrm{COu}}$ & 1 & 1 & 1 & 1 & 1 & 1 \\
\hline$Y_{\mathrm{cOb}}$ & 1 & 1 & 1 & 1 & 1 & 1 \\
\hline
\end{tabular}

Table IV. Activation Energies of the Two Materials

\begin{tabular}{|c|c|c|c|c|c|c|c|c|c|c|c|}
\hline \multicolumn{2}{|c|}{ Parameters } & \multirow{2}{*}{$\begin{array}{l}K_{1 u} \\
\left(s^{-1}\right)\end{array}$} & \multirow{2}{*}{$\begin{array}{l}K_{1 b} \\
\left(L^{-1} l^{-1}\right. \\
\left.s^{-1}\right)\end{array}$} & \multirow{2}{*}{$\begin{array}{l}\mathrm{K}_{2} \\
\left(\mathrm{~L} \mathrm{~mol}^{-1}\right. \\
\left.\mathrm{s}^{-1}\right) \\
0\end{array}$} & \multirow{2}{*}{$\begin{array}{l}\mathrm{K}_{3} \\
\left(\mathrm{~L} \mathrm{~mol}^{-1}\right. \\
\left.\mathrm{s}^{-1}\right)\end{array}$} & \multirow{2}{*}{$\begin{array}{l}\mathrm{K}_{4} \\
\left(\mathrm{~L} \mathrm{~mol}^{-1}\right. \\
\left.\mathrm{s}^{-1}\right) \\
0\end{array}$} & \multirow{2}{*}{$\begin{array}{l}\mathrm{K}_{5} \\
\left(\mathrm{~L} \mathrm{~mol}^{-1}\right. \\
\left.\mathrm{s}^{-1}\right) \\
0\end{array}$} & \multirow{2}{*}{$\begin{array}{l}\mathrm{K}_{6} \\
\left(\mathrm{~L} \mathrm{~mol}^{-1}\right. \\
\left.\mathrm{s}^{-1}\right)\end{array}$} & \multirow{2}{*}{$\begin{array}{l}\mathrm{K}_{\mathrm{S} 1} \\
\left(\mathrm{~L} \mathrm{~mol}^{-1}\right. \\
\left.\mathrm{s}^{-1}\right)\end{array}$} & \multirow{2}{*}{$\begin{array}{l}\mathrm{K}_{\mathrm{s} 2} \\
(\mathrm{~L} \mathrm{~mol}-1 \\
\left.\mathrm{s}^{-1}\right)\end{array}$} & \multirow{2}{*}{$\begin{array}{l}\mathrm{K}_{\mathrm{PHOS}} \\
\left(\mathrm{L} \mathrm{mol}^{-1}\right. \\
\left.\mathrm{s}^{-1}\right) \\
96.27\end{array}$} \\
\hline Activation & RPP & & & & & & & & & & \\
\hline $\begin{array}{l}\text { energy } \\
\left(\mathrm{KJ} \mathrm{Mol}^{-1}\right)\end{array}$ & RPP-CF180 & 125.64 & 109.1 & 0 & 54.83 & 0 & 0 & 27.381 & 46.75 & 10.4 & 93.53 \\
\hline
\end{tabular}
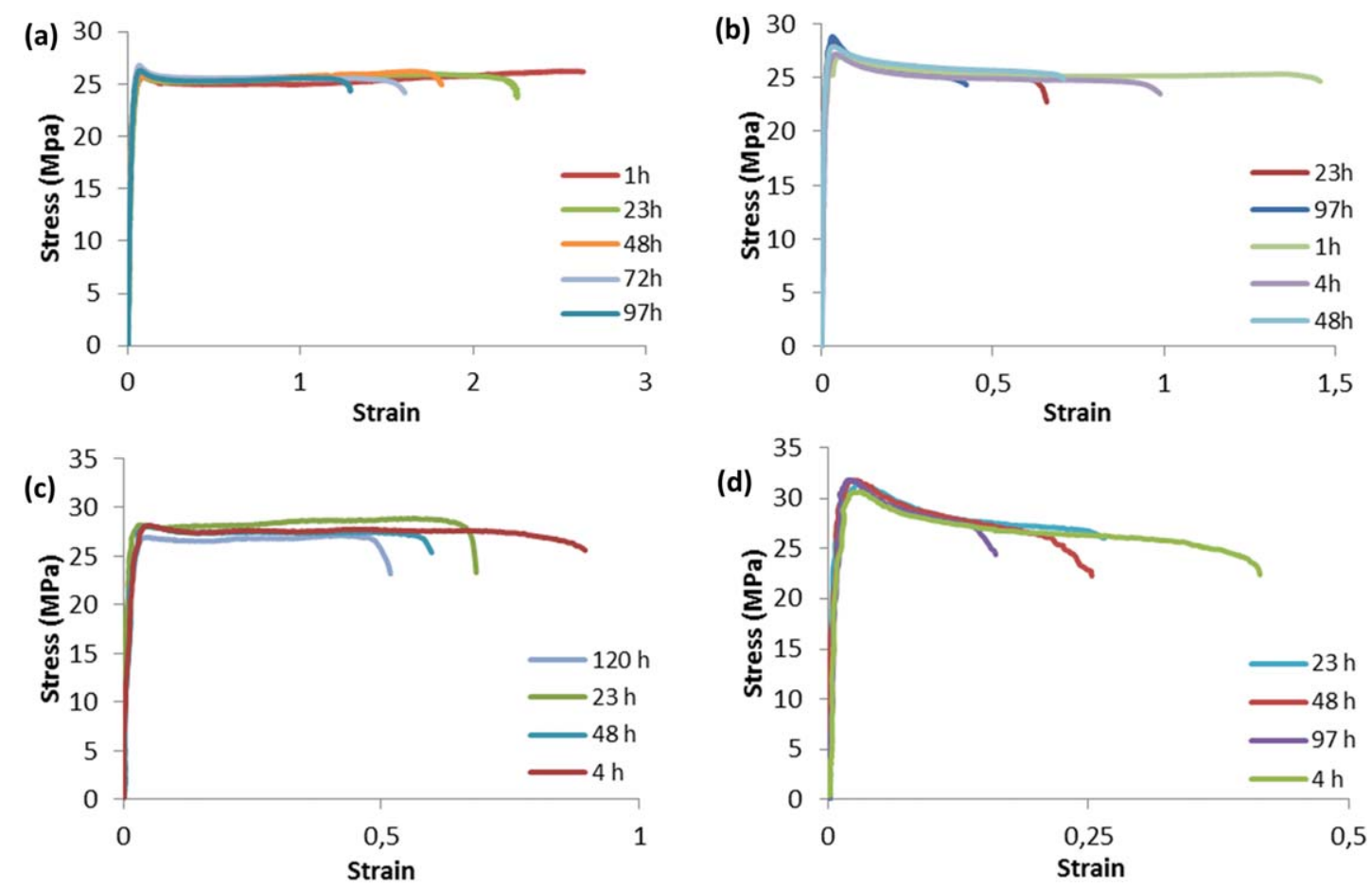

Figure 9. Stress-strain curves at quasi-static and dynamic loading: (a) RPP, (b) RPP-CF180 at $10 \mathrm{~mm} / \mathrm{min}$, (c) RPP, (d) RPP-CF180 at $10 \mathrm{~s}^{-1}$ for $140{ }^{\circ} \mathrm{C}$. [Color figure can be viewed at wileyonlinelibrary.com] 

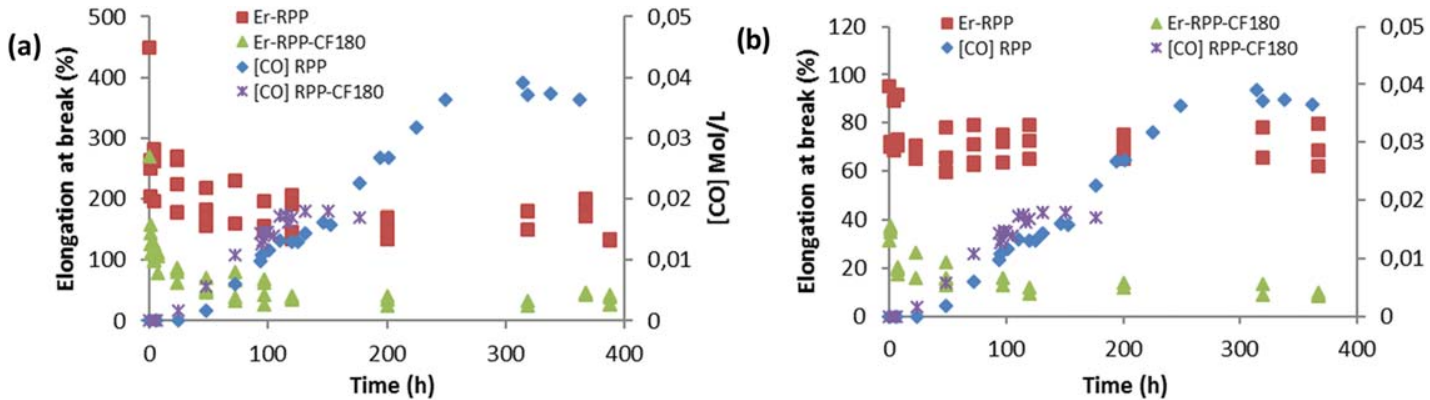

Figure 10. Elongation at break evolution at quasi-static and dynamic loading for $140{ }^{\circ} \mathrm{C}$ : (a) RPP and (b) RPP-CF180. [Color figure can be viewed at wileyonlinelibrary.com]

reached. In high strain rate loading, the two materials show a less important drop during the induction period, $25 \%$ and $34 \%$ for the matrix and the composite, respectively, but a same behavior of a small decrease till the end of oxidation. This phenomenon is due to the embrittlement of the matrix during exposure and to the weakening of the fiber/matrix interface in the case of the composite.

From an experimental point a view, during the induction period the carbonyl value is taken equal to zero because it remains too small and it is difficult to detect any changes. But in reality, it is not the case. In fact during this period, the polymer chains break to initiate the formation of radicals and then $\mathrm{POOH}$ responsible for carbonyl growth. In the case of the studied materials, the embrittlement occurs from the first moments of exposure during the induction period, so one can wonder what really happened during this duration. By taking a close look at the induction period given by the model when the embrittlement at the quasi-static loading of the matrix and composite occurs, as represented in Figure 11, it is clear that the carbonyls start to appear but with a very small concentration that does not exceed $10^{-4} \mathrm{~mol} / \mathrm{L}$. Thus, it is possible not only to link the elongation at break with exposure time (Figure 10) but also with the quantity of $[\mathrm{CO}]$ present within the materials during the induction period as shown in Figure 12. As studied in the literature, the oxidation due to the penetration of oxygen in a thick exposed material occurs only at the surface, 100-200 $\mu \mathrm{m}$, leading to an embrittlement and then final failure. In the case of the current study, the concentration of carbonyls formed at the beginning of exposure, even if it is too small considering their value after the induction time, participate in the embrittlement of the composite and the matrix causing a drop in the elongation at break. Hence, it is possible to couple the affected
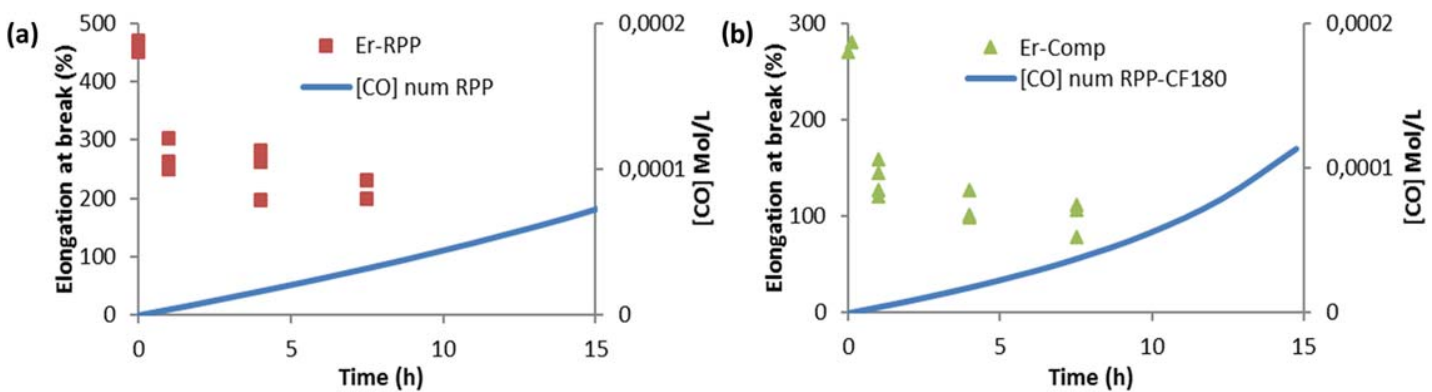

Figure 11. Comparison between elongation at break and numerical carbonyl growth at QS loading at $140^{\circ} \mathrm{C}$ : (a) RPP and (b) RPP-CF180. [Color figure can be viewed at wileyonlinelibrary.com]

(a)

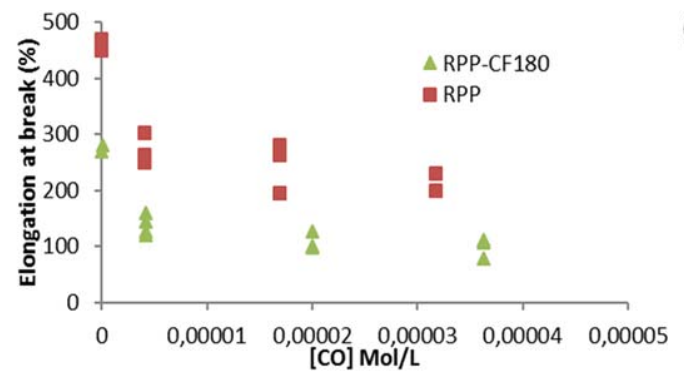

(b)

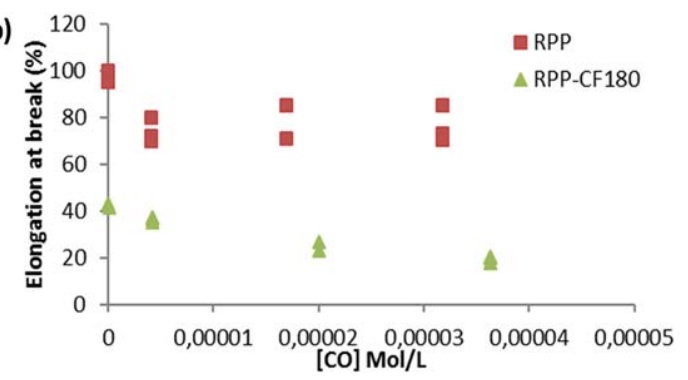

Figure 12. Elongation at break evolution Vs carbonyl build-up for RPP and RPP-CF180 at $140{ }^{\circ} \mathrm{C}$ : (a) Quasi-static, (b) Dynamic. [Color figure can be viewed at wileyonlinelibrary.com] 
mechanical properties with a quantified parameter directly linked to the oxidation.

A direct relation between the oxidation products, $[\mathrm{CO}]$, and the elongation at break has been identified. Indeed, the oxidation is a surface phenomenon which affects on one hand the cracking of the matrix and on the other hand the fiber/matrix interface weakening. Thus, surface micro-cracking is favored and propagates into the material leading to failure. It has been shown that embrittlement of the surface by oxidation justifies the decrease of the elongation at break. Moreover, the results presented in this work make it possible to quantify this relationship. Further analyses dealing with the surface oxidative embrittlement phenomena will be the subject of a forthcoming publication.

\section{CONCLUSIONS}

In this article, the stabilization by phenol and phosphites of a new recycled blend and its reinforced carbon fibers composite has been studied during thermal oxidation at $140^{\circ} \mathrm{C}$. The induction time of the composite appeared to be shorter than that of the matrix due to a decrease in the concentration of the antioxidant during the extrusion and the injection molding processes. Several methods were used in the aim of determining the different evolutions of antioxidants concentration and carbonyl build-up through aging. A kinetic model which is based on a classic mechanistic scheme that takes into account in one hand uni- and bimolecular hydroperoxide decomposition and in the other hand the antioxidants effect was proposed and the elementary rate constants of the model were determined by inverse method. The obtained simulations of kinetic curves of carbonyl growth and the antioxidants' consumption showed a good correlation with those obtained experimentally with a reasonable physical loss. Thermal aging effect on the mechanical behavior of the studied materials was characterized under quasi-static and high strain loading. At both strain rates the overall mechanical behavior was not affected during thermal aging except for the strain at break which shows a decrease from the very first moment of exposure due to matrix embrittlement and fiber/ matrix weakening. At low strain range, the drop of the elongation at break is higher than at high strain load. In fact, it is about $40 \%$ compared to $25 \%$ for the matrix and $45 \%$ compared to $34 \%$ in the case of the composite.

In further study, the obtained results will be coupled with damage investigation at a micro scale in order not only to characterize but also to quantify the damage initiation and kinetics during thermal aging at different temperature of exposure.

\section{REFERENCES}

1. Bos, G. EU Waste Legislation and the Composites Industry. Seminar on Recycling of Composite Materials, IFP SICOMP, Molndal, Sweden, 14th-15th May 2002.

2. Pickering, S. J. Compos. Part A 2006, 37, 1206.

3. Pimenta, S.; Pinho, S. T. Waste Manag. 2011, 31, 378.
4. Feih, S.; Mouritz, A. P.; Case, S. W. Compos. A: Appl. Sci. Manuf. 2015, 76, 255.

5. Yang, L.; Sáez, E. R.; Nagel, U.; Thomason, J. L. Compos. A: Appl. Sci. Manuf. 2015, 72, 167.

6. Sasse, F.; Emig, G. Chem. Eng. Technol. 1998, 21, 777.

7. Schwarzenbach, K.; Gilg, B.; Muller, D.; Knobloch, G.; Pauquet, J. R.; Rota-Graziosi, P. Plastics Additives Handbook, 5th ed.; Zweifel, H., Ed.; Hanser Gardner Publications: Cincinnati, $\mathrm{OH}, 2001$.

8. Calvert, P. D.; Billingham, N. C. J. Appl. Polym. Sci. 1979, 24, 357.

9. Billingham, N. C. Plastics Additives Handbook, 5th ed.; Zweifel, H., Ed.; Hanser Gardner Publications: Cincinnati, OH, 2001; p 1019.

10. Ritter, A.; Michel, E.; Schmid, M.; Affolter, S. Polym. Test. 2005, 24, 498.

11. Bataillard, P.; Thomas, M. Plastics Additives Handbook, 5th ed.; Zweifel, H., Ed. Hanser Gardner Publications: Cincinnati, OH, 2001; p 1047.

12. Lundbäck, M.; Strandberg, C.; Albertsson, A.-C.; Hedenqvist, M. S.; Gedde, U. W. Polym. Degrad. Stabil. 2006, 91, 1071.

13. Strandberg, C.; Burman, L.; Albertsson, A.-C. Eur. Polym. J. 2006, 42, 1855.

14. Rosa, D. S.; Sarti, J.; Mei, L. H. I.; Filho, M. M.; Silveira, S. Polym. Test. 2000, 19, 523.

15. Richaud, E. Eur. Polym. J. 2013, 49, 2223.

16. Richaud, E.; Monchy-Leroy, C.; Colin, X.; Audouin, L.; Verdu, J. Polym. Degrad. Stabil. 2009, 94, 2004.

17. Bair, H. E. Polym. Eng. Sci. 1973, 13, 435.

18. Naskar, K.; Kokot, D.; Noordermeer, J. W. M. Polym. Degrad. Stabil. 2004, 85, 831.

19. Richaud, E.; Fayolle, B.; Verdu, J. Polym. Degrad. Stabil. 2011, 96, 1.

20. Meftah, H.; Tamboura, S.; Fitoussi, J. et al. Appl Compos Mater (2017). https://doi.org/10.1007/s10443-017-9632-6

21. Zahradníčková, A.; Sedlár, J.; Dastych, D. Polym. Degrad. Stabil. 1991, 32, 155.

22. Földes, E.; Maloschik, E.; Kriston, I.; Staniek, P.; Pukánszky, B. Polym. Degrad. Stabil. 2006, 91, 479.

23. Rugg, F. M.; Smith, J. J.; Bacon, R. C. J. Polym. Sci. 1954, 13,535 . Volume Issue

24. Lacoste, J.; Carlsson, D. J. J. Polym. Sci. Part A: Polym. Chem. 1992, 30, 493.

25. Djouani, F.; Richaud, E.; Fayolle, B.; Verdu, J. Polym. Degrad. Stabil. 2011, 96, 1349.

26. Djouani, F.; Patel, B.; Richaud, E.; Fayolle, B.; Verdu, J. Fuel 2012, 502.

27. de Lima, J. A.; Fitaroni, L. B.; Chiaretti, D. V. A.; Kaneko, M. L. Q. A.; Cruz, S. A. Chemistry 2017, 30, 504.

28. Vogel, P. Ecole Polytechnique Fédérale de Lausanne (EPFL), « Théorie « simpliste » de la couleur (spectroscopie UV-Visible) » 20.

29. Audouin, L.; Gueguen, V.; Tcharkhtchi, A.; Verdu, J. J. Polym. Sci. Part A: Polym. Chem. 1995, 33, 921. 
30. Allen, N. S.; Chirinis-Padron, A.; Henman, T. J. Polym. Degrad. Stabil. 1985, 13, 31.

31. Pospíšil, J. Polym. Degrad. Stabil. 1991, 34, 85.

32. Pospíšil, J. Polym. Degrad. Stabil. 1993, 39, 103.

33. Richaud, E.; Farcas, F.; Fayolle, B.; Audouin, L.; Verdu, J. Polym. Degrad. Stabil. 2007, 92, $118 \mathrm{e} 24$.
34. Gillen, K. Y.; Wise, J.; Clough, R. Polym. Degrad. Stabil. 1995, 47, 149e61.

35. Fayolle, B.; Audouin, L.; Verdu, J. Polym. Degrad. Stabil. 2000, 70, 333.

36. Fayolle, B.; Audouin, L.; Verdu, J. Polymer 2004, 45, 4323. 